\title{
Antibiogram Profile of Antibacterial Multidrug Resistance in Democratic Republic of Congo: Situation in Bukavu City Hospitals
}

Justin Ntokamunda Kadima ( $\sim$ ntokamunda13@gmail.com )

Official University of Bukavu

Christian Ahadi Irenge

Official University of Bukavu

Patient Birindwa Mulashe

Official University of Bukavu

Félicien Mushagalusa Kasali

Official University of Bukavu

Patient Wimba

Official University of Bukavu

\section{Research Article}

Keywords: Multidrug resistance, Bacteria, Antibiogram, Bukavu

Posted Date: February 10th, 2021

DOI: https://doi.org/10.21203/rs.3.rs-153115/v1

License: @ (i) This work is licensed under a Creative Commons Attribution 4.0 International License. Read Full License 


\section{Abstract \\ Background}

Bacterial strains carrying multidrug resistance traits are gaining ground worldwide, especially in countries with limited resources. This study aimed to evaluate the spreading of multidrug-resistant bacteria strains in Bukavu city hospitals in the Democratic Republic of Congo.

\section{Methods}

We analyzed 758 antibiogram data recorded in files of patients consulted between January 2016 and December 2017 at three reference hospitals selected as sentinel sites, namely the Panzi General Reference Hospital (HGP), BIO -PHARM hospital (HBP), and Saint Luc Clinic (CSL).

\section{Results}

Of 758 isolates tested, the laboratories identified 12 bacterial strains in 712 isolates, of which $223(29.42 \%)$ presented MDR profile, including Escherichia coli (11.48\%), Klebsiella pneumonia (6.07\%), Enterobacter (5.8\%), Staphylococcus aureus and coagulase-negative staphylococci (1.58\%), Proteus mirabilis (1.85\%), Salmonella enterica (1.19\%), Pseudomonas aeruginosa (0.53\%), Streptococcus pneumonia $(0.4 \%)$ ), Citrobacter $(0.13 \%)$, Neisseria gonorrhea $(0.13 \%)$, Enterococcus faecalis $(0.13 \%)$ and Morganella morganii $(0.13 \%)$. Infected patients were significantly adults $(73.1 \%$ vs. $21.5 \%)$ compared to children and mainly women $(63.7 \%$ vs. $30.9 \% ; p=0.001)$.

\section{Conclusion}

The observed expansion requires that hospital therapeutic committees set up an effective clinical management system and define the right combinations of antibiotics.

\section{Background}

By definition, Multidrug-Resistant (MDR) microbes are species non-sensitive to at least one agent in three or more antimicrobial categories [1]. Extended Drug-Resistant (XDR) strains resist at least one agent in all but two or fewer antimicrobial groups (bacterial isolates remain susceptible to only one or two classes. PanDrug-Resistant (PDR) strains are resistant to all agents from all categories of antimicrobials [1, 2]. As pointed out by the World Organization for Animal Health (WOAH), the Food and Agriculture Organization of the United Nations (FAO), and the World Health Organization (WHO), MDR microorganisms have dangerously reached high levels in all parts of the world, especially in low-income regions [3-6]. The pathogens responsible for tuberculosis (TB), malaria, sexually transmitted infections (STI), typhoid fever, bacterial dysentery, and pneumonia now exhibit MDR characteristics. Up to 17\% of TB cases are MDR, and XDR of TB is increasingly observed worldwide [7].

The hospital is the primary source of MDR infections caused by Staphylococcus aureus (SA), Enterococcus faecium (EF), Escherichia coli(EC), Klebsiella pneumoniae(KP), Enterobacter spp. (EB), Citrobacter spp.(CB), Pseudomonas aeruginosa(PA), and Acinetobacter calcoaceticus(AC) [8]. Up to 10\% of hospitalized patients contract nosocomial infections [9], but the community-based transmission is also dangerously gaining ground. The death rate associated with diseases caused by bacteria resistant to antibiotics is often higher than that of susceptible bacteria [7, 10]. Resistance often leads to treatment failure and thus increases mortality from infections. When an infection can no longer respond to 
treatment with a first-line antibiotic, more expensive drugs should be used. Collaterally, prolonging illness and treatment increases health care costs, as well as the financial burden on families and society [7, 11]. Many factors triggering microbial resistance are known, mainly the misuse or irrational use of antibiotics. In 20 to $50 \%$ of cases, their use in humans is unnecessary, and in animals, it is questionable in 40 to $80 \%$ cases [12].

The increasing proportion of poor-quality generic drugs is a growing concern in the sub-Saharan Africa region [12-14]. There are multiple drawbacks to using poor-quality antimicrobial drugs; that lead to microbial resistance, treatment failure, exacerbation of the disease, and increased death rates. The WHO and the US Centers for Disease Control and Prevention (CDCP) have recognized the importance of studying the factors of emergence and risk of resistance and the need to establish control $[3,8,15]$. The MDR scoreboard itself in the Democratic Republic of Congo (DRC) is not clearly defined. Epidemiological investigations are essential to monitoring the spread of MDR as in other countries with limited resources [16-18]. This study aimed to profile the spread of MDR bacterial infections in Bukavu, a town in eastern DRC.

\section{Methods}

\section{Study design and data collection}

The study was a retrospective cross-sectional analysis of the antibiogram data recorded in the files of patients consulted between January 2016 and December 2017. Three reference hospitals were selected as sentinel sites, namely the Panzi General Reference Hospital (HGP), BIO -PHARM hospital (HBP), and Saint Luc Clinic (CSL). Laboratories performed antimicrobial sensitivity tests on blood, urine, cerebrospinal fluid, and other samples, according to standard recommendations [19-21]. The susceptibility outcome was considered sensitive or resistant based on the inhibition diameter and according to data published in the 2017 CA-SFM recommendations.

\section{Ethical considerations}

All methods were carried out in accordance with relevant guidelines and regulations. All experimental protocols were approved by the research committee of the Faculty of Medicine (UOB). The clinical directors of the study hospitals allowed the collection of data. As retrospective study, informed consent was waived by institutional ethics review board of the Official University of Bukavu. We assured for the confidentiality of individual patient information.

\section{Data analysis}

The SPSSv20 statistical software and Windows Excel 10 served to run descriptive statistics with a statistically significant difference set at $p<0.05 ; 95 \%$, regarding the demographics of patients with MDR, the frequency of MDR strains in each hospital, and each biological sample.

\section{Results}

\section{Identification and Prevalence of MDR strains}

Table 1 shows the total number $(\mathrm{N})$ of each strain identified, the prevalence (\%) of MDR and NMDR strains by column and row, as well as the ratio of MDR/NMDR. Of 758 isolates examined, laboratory technicians identified 12 bacteria present in $712(93.93 \%)$ samples and did not identify the strains in $46(6.07 \%)$ samples. Of those identified, $535(70.58 \%)$ were NMDR, and 223 (29.42\%) MDR. The column \% shows that the most prevalent were EC (49.34\%), KP (11.87\%), EB (11.61\%), and $S A(11.61 \%)$. Individual MDR frequencies were $E C(11.48 \%), K P(6.07 \%), \mathrm{EB}(5.8 \%), S A(1.58 \%), P M(1.85 \%)$, $S(1.19 \%), P A(0.53 \%), S P(0.40 \%), C B(0.13 \%), N G(0.13 \%), E F(0.13 \%)$ and $M M(0.13 \%)$. By row, out of $374 E C$ isolates, there were 287 (76.74\%) NMDR and 87 (23.26\%) MDR, resulting in an MDR / NMDR ratio $=0.303$. All 46 unidentified isolates were NMDR. 
Table 1

Identity and Frequency of MDR and non-MDR strains

\begin{tabular}{|llllllllll|}
\hline Strains name & Total & MDR & NMDR & Total & MDR & NMDR & MDR & NMDR \\
\hline & N & N & N & C\% & C\% & C\% & R\% & R\% & Ratio \\
\hline Escherichia coli (EC) & 374 & 87 & 287 & 49.34 & 11.48 & 37.86 & 23.26 & 76.74 & 0.303 \\
\hline Klebsiella pneumoniae (KP) & 90 & 46 & 44 & 11.87 & 6.07 & 5.80 & 51.11 & 48.89 & 1.045 \\
\hline Enterobacter spp (EB) & 88 & 44 & 44 & 11.61 & 5.80 & 5.80 & 50.00 & 50.00 & 1.000 \\
\hline Staphylococcus aureus (SA) & 88 & 12 & 76 & 11.61 & 1.58 & 10.03 & 13.64 & 86.36 & 0.158 \\
\hline Proteus mirabilis (PM) & 28 & 14 & 14 & 3.69 & 1.85 & 1.85 & 50.00 & 50.00 & 1.000 \\
\hline Salmonella enterica (SE) & 21 & 9 & 12 & 2.77 & 1.19 & 1.58 & 42.86 & 57.14 & 0.750 \\
\hline Pseudomonas aeruginosa (PA) & 12 & 4 & 8 & 1.58 & 0.53 & 1.06 & 33.33 & 66.67 & 0.500 \\
\hline Streptococcus pyogenes (SP) & 7 & 3 & 4 & 0.92 & 0.40 & 0.53 & 42.86 & 57.14 & 0.750 \\
\hline Citrobacter(CB) & 1 & 1 & 0 & 0.13 & 0.13 & 0 & 100 & 0 & - \\
\hline Enterococcus faecalis (EF) & 1 & 1 & 0 & 0.13 & 0.13 & 0 & 100 & 0 & - \\
\hline Morganella morganii (MM) & 1 & 1 & 0 & 0.13 & 0.13 & 0 & 100 & 0 & - \\
\hline Neisseria gonorrhea (NG) & 1 & 1 & 0 & 0.13 & 0.13 & 0 & 100 & 0 & - \\
\hline Strains unidentified & 46 & 0 & 46 & 6.07 & 0.00 & 6.07 & 0.00 & 100 & 0.00 \\
\hline Total isolates & 758 & 223 & 535 & 100 & 29.42 & 70.58 & 29.42 & 70.58 & 0.417 \\
\hline C\% (column percentage); R\%(row percentage) & & & & & & \\
\hline
\end{tabular}

Frequency of MDR strains disaggregated by age, gender, hospital, specimens

Figure 1 shows that most infected patients were adults $(73.1 \%)$ compared to children $(21.5 \%, p=0.036)$. EC, KP, EB, SA, $\mathrm{PM}$, and $\mathrm{SE}$ are found in both age groups, while PA, SP, CB, EF, NG, and MM not found in paediatric patients. Likewise, most women $(63.7 \%)$ were infected compared to men $(30.9 \% ; p=0.001)$. PA has been found much more in men than in women; $\mathrm{CB}, \mathrm{EF}$, and $\mathrm{MM}$ in males only. The only case of NG was from a woman. In total, $53.8 \%$ of the 223 MDR strains came from the HGP hospital, 30.9\% from the HBP hospital, and 15.2\% from CSL ( $p=0.001)$. EC, KP, and EB strains were isolated from all three hospitals; the other strains occurred in only one or two hospitals. The majority of biological samples tested were urinary tract infections (61.8\%) followed by skin pus (23.8\%), ear pus, vaginal secretion, stool, sputum, blood, and cerebrospinal fluid. EC was found in UT (80.4\%), skin pus (8\%), vagina (10.3\%); KP in UT (56.5\%) and skin pus (41.1\%); EB in UT (47.7\%), skin pus (20.5\%), vagina (2.3\%), stool (22.7\%), blood (2.3\%), cephalospinal fluid (2.3\% ); SA in UT (50\%), skin pus (33.3\%, ear pus (16.7\%); PM in UT (35.7\%), skin pus (50\%, blood (7.1\%) ; SE in UT (55.5\%), skin pus (33.3\%), ear pus (11.1\%); BP in UT (25\%), skin pus (50\%), ear pus (25\%); SP in UT (33.3\%), skin pus (66.7\%); CB in spindle (100\%); EF in UT (100\%); NG in UT (100\%); MM in skin pus (100\%).

\section{Susceptibility of MDR isolates to antibiotics used in hospitals}

Table 2 shows the number of each strain exposed to a given antibiotic and, in parentheses, the percentage of susceptible strains. 
For example, to ciprofloxacin, only $25 \%$ of $76 \mathrm{EC}$ isolates, $12.8 \%$ of $39 \mathrm{KP}$ isolates, $17.5 \%$ of $40 \mathrm{~EB}$ isolates, $40 \%$ of $10 \mathrm{SA}$ isolates, $0 \% 4 \mathrm{PA}$ isolates, and $0 \%$ of $1 \mathrm{MM}$ isolates were susceptible. Against meropenem, $40.8 \%$ of the $49 \mathrm{EC}$ strains tested were sensitive. For EC strains, we found 25\% ciprofloxacin-sensitive, $27.3 \%$ moxifloxacin-sensitive, $9.3 \%$ clavulanic amoxicillin-sensitive, 0\% ampicillin sensitive, 40.8\% meropenem-sensitive, 60\% gentamicin-sensitive, 26.5\%

cotrimoxazole-sensitive, and $27.8 \%$ chloramphenicol-sensitive. Likewise, $21.2 \%$ of EB were meropenem-sensitive, $80 \%$ of SA were chloramphenicol sensitive, and $40 \%$ sensitive to ciprofloxacin. Meanwhile, $33 \%$ of SP were susceptible to ciprofloxacin, and $66.7 \%$ susceptible to meropenem. Almost all MDR bacterial strains were resistant to ampicillin. 
Table 2

Number of each strain and percentage (\%) of sensitive isolates to each antibiotic

\begin{tabular}{|c|c|c|c|c|c|c|c|c|c|c|c|}
\hline ABT categories & EC & KP & EB & SA & PM & SE & PA & SP & EF & MN & NG \\
\hline \multirow[t]{2}{*}{ Ciprofloxacin } & 76 & 39 & 40 & 10 & 14 & 7 & 4 & 3 & 1 & 1 & 1 \\
\hline & (25.0) & (12.8) & (17.5) & $(40.0)$ & $(22.4)$ & (42.9) & (0) & (33.3) & (0) & (0) & (0) \\
\hline \multirow[t]{2}{*}{ Norfloxacin } & 8 & 4 & 3 & 2 & 1 & 2 & 1 & 1 & & 1 & \\
\hline & (12.5) & $(0)$ & (0) & (0) & (0) & $(0)$ & $(0)$ & $(0)$ & & $(0)$ & \\
\hline \multirow[t]{2}{*}{ Moxifloxacin } & 11 & 15 & 6 & & & 1 & & & & & 1 \\
\hline & (27.3) & $(0)$ & (0) & & & (0) & & & & & (0) \\
\hline \multirow[t]{2}{*}{ Nalidixic acid } & 10 & 2 & 4 & & 1 & 2 & & & & & \\
\hline & (20.0) & (0) & (0) & & (0) & (0) & & & & & \\
\hline \multirow[t]{2}{*}{ Cotrimoxazole } & 68 & 33 & 33 & 4 & 12 & 8 & 2 & 2 & 1 & 1 & 1 \\
\hline & $(26.5)$ & $(0)$ & (18.2) & $(0)$ & $(0)$ & $(0)$ & (0) & $(50.0)$ & $(100)$ & $(0)$ & (0) \\
\hline \multirow[t]{2}{*}{ Amoxi-Clav } & 54 & 36 & 34 & 5 & 11 & 4 & & 3 & 1 & 1 & \\
\hline & $(9.3)$ & $(0)$ & $(9.8)$ & $(0)$ & $(0)$ & $(0)$ & & $(0)$ & (0) & $(0)$ & \\
\hline \multirow[t]{2}{*}{ Ampicillin } & 15 & 28 & 15 & 3 & 10 & 1 & 2 & & 1 & 1 & \\
\hline & (0) & $(0)$ & $(0)$ & $(0)$ & (0) & $(0)$ & (0) & & (0) & $(0)$ & \\
\hline \multirow[t]{2}{*}{ Oxacillin } & 6 & 8 & 4 & 2 & 2 & 2 & 1 & & & & \\
\hline & (0) & $(0)$ & (0) & (0) & (0) & (0) & (0) & & & & \\
\hline \multirow[t]{2}{*}{ Ceftriaxone } & 69 & 44 & 36 & 11 & 13 & 7 & 4 & 3 & & 1 & \\
\hline & (4.3) & $(6.8)$ & $(0)$ & (18.2) & $(0)$ & (14.3) & (0) & $(0)$ & & $(0)$ & \\
\hline \multirow[t]{2}{*}{ Cefuroxime } & 2 & 1 & 3 & & & & & & & & \\
\hline & (0) & (0) & (0) & & & & & & & & \\
\hline \multirow[t]{2}{*}{ Meropenem } & 49 & 44 & 33 & 8 & 14 & 8 & 2 & 3 & 1 & 1 & \\
\hline & $(40.8)$ & $(4.5)$ & $(21.2)$ & $(25)$ & $(7.1)$ & (25) & $(0)$ & $(66.7)$ & $(100)$ & $(0)$ & \\
\hline \multirow[t]{2}{*}{ Imipenem } & & & 1 & & & & & & & & \\
\hline & & & $(100)$ & & & & & & & & \\
\hline \multirow[t]{2}{*}{ Azythromycin } & 71 & 40 & 39 & 8 & 12 & 6 & 3 & 2 & 1 & 1 & 1 \\
\hline & $(22.6)$ & (7.5) & $(7.9)$ & $(0)$ & $(0)$ & (0) & (0) & $(0)$ & (0) & $(0)$ & (0) \\
\hline \multirow[t]{2}{*}{ Erythromycin } & 9 & & 8 & 1 & & & & & & & \\
\hline & $(0)$ & & $(0)$ & (0) & & & & & & & \\
\hline \multirow[t]{2}{*}{ Amikacin } & 7 & 1 & 5 & 2 & 1 & 1 & & 1 & 1 & & \\
\hline & (0) & (0) & $(0)$ & $(0)$ & $(0)$ & (0) & & (0) & (100) & & \\
\hline \multirow[t]{2}{*}{ Gentamicin } & 5 & & 2 & & & 1 & & 2 & & & \\
\hline & (60) & & (0) & & & (0) & & (0) & & & \\
\hline
\end{tabular}




\begin{tabular}{|c|c|c|c|c|c|c|c|c|c|c|c|}
\hline ABT categories & EC & KP & EB & SA & PM & SE & PA & SP & $\mathrm{EF}$ & MN & NG \\
\hline \multirow[t]{2}{*}{ Kanamycin } & & & 1 & & & & & & & & \\
\hline & & & (100) & & & & & & & & \\
\hline \multirow[t]{2}{*}{ Chloramphenicol } & 18 & 33 & 18 & 5 & 9 & 5 & 3 & 1 & & & \\
\hline & $(27.8)$ & (6.1) & (0) & (80) & $(11.1)$ & (40) & (0) & (0) & & & \\
\hline \multirow[t]{2}{*}{ Clindamycin } & 18 & & & 1 & 1 & & 2 & 2 & & & \\
\hline & (5.6) & & & (0) & (0) & & (0) & (0) & & & \\
\hline \multirow[t]{2}{*}{ Tetracycline } & 1 & & 1 & 1 & & & & & & 1 & \\
\hline & (0) & & (0) & (0) & & & & & & (100) & \\
\hline \multirow[t]{2}{*}{ Doxycycline } & 24 & & 10 & & 1 & & 1 & & & & 1 \\
\hline & (25) & & (30) & & (0) & & (100) & & & & (100) \\
\hline
\end{tabular}

\section{Discussion}

In 2014, the WHO [22] had expressed the need to establish a global surveillance system for antimicrobial resistance, then launched in October 2015, the Global Antimicrobial Surveillance System (GLASS), in close collaboration with various existing networks based on experience from other WHO surveillance programs. This study aimed to contribute to such a need. The results identified 12 bacterial strains were in the samples taken from 758 cultures, mainly the EC strain. The profiles found here are comparable to those reported in other studies in Africa, the USA, and Europe [24], as illustrated below. Some isolates might even be XDR bacteria, but we did not separate them because the data did not come from a controlled study. The GLASS report [22] revealed that the most common MDR bacteria were Escherichia coli, Klebsiella pneumoniae, Staphylococcus aureus, and Streptococcus pneumoniae, followed by Salmonella spp. The $29.4 \%$ median rate of MDR strains found in Bukavu ranges between 23\% in the USA and 37\% in India. In the USA, a study [24] conducted in community hospitals revealed $23 \%$ of MDR pathogens, of which the three most common were $S A(28 \%), E C(24 \%)$, and coagulase-negative staphylococci (10\%); the infecting organism varied according to the place of acquisition. In Rwanda, the prevalence of MDR strains was $28 \%$ based on three primary data [26]. Studies in India found 37.1\% MDR bacteria, $13.8 \%$ XDR and 0\% PDR $[2,25]$. Despite the differences in the prevalence levels reported worldwide, the results support the alert on the increase in MDR bacteria around the world.

Aggregation of results by the hospital showed that more cases were from GHP (53.8\%), followed by HBP (30.9\%) and CSL $(15.2 \%)$. The significant difference $(p=0.001)$ is only related to the size of each hospital. The profile also indicated that most isolates were from sexually transmitted UTIs (61.8\%) followed by skin infections (23.8\%). The majority of people carrying MDR strains were adults (60\%), as expected since children are less prone to UTIs. The high percentage of women (51\%) is due to anatomical causes (proximity to the vaginal and anal openings), poor hygiene habits, sexual intercourse, and pregnancy $[17,23]$.

The susceptibility profiles of the strains varied according to the classes of antibiotics. Regarding resistance to the betalactam category, the case of ampicillin and amoxicillin is striking. The test shows that these drugs are less effective against almost all strains. Many bacteria are also resistant to cephalosporins in this study. However, our previous research had shown that they are currently still widely prescribed and also used as self-medication in Bukavu [17, 18]. A review article [16] reports that MDR (penicillin + two other classes) is 25\% in Africa, $20 \%$ in Latin America, $12 \%$ in Eastern Europe, $18 \%$ in Western Europe, and $26 \%$ in the USA. Data from bacterial resistance surveillance networks show that the distribution of 3rd generation cephalosporin-resistant Enterobacteriaceae species has increased significantly [22, 27]. 
According to the authors, this resistance mainly concerns the production of extended-spectrum beta-lactamase (ESBL) and, to a lesser extent, plasma cephalosporinases (AmpC). For instance, the resistance of KP to third-generation cephalosporin is critical on a large scale in all WHO regions of the Americas, the Western Pacific, the Eastern Mediterranean, and the European Region [22]. Community-based infection with resistant E.coli producing extendedspectrum beta-lactamases is ubiquitous in Asia, the Middle East, South America, and parts of Europe [28].

Regarding aminoglycosides (AGs), gentamicin was more effective against EC (60\%), resistant to $P A, K P$, and Salmonella. However, it is used mainly in combination with amoxicillin and azithromycin [18]. In the study by Bala et al. [29], no MDR isolate of gentamicin appeared. These in vitro results suggest that gentamicin may be an effective treatment option for MDR strains. In Bukavu hospitals, gentamicin is used mainly in combination with amoxicillin and azithromycin [18]. Parenteral administration of AGs, which limits their use as self-medication, partly explains their preserved efficacy. By far, the most common mechanism of resistance to AGs is the inactivation of these antibiotics by enzymes modifying their structure $[30,31]$.

This study showed high resistance of many infections to second-generation quinolones. Only $25 \%$ of the 76 EC strains were susceptible to ciprofloxacin, which backs what some studies reported in Asia and Africa [16, 22, 32-34]. EC ST131 is a clone of MDR disseminated worldwide that presents resistance to fluoroquinolones in addition to the production of ESBL CTX-M. EC ST131 strains tend to induce pyogenic liver abscesses and sometimes metastatic infections, including meningitis. The median resistance of SE Typhi to nalidixic acid is between $15.4-43.2 \%$ for pathogens isolated from patients with severe illness [28, 35-37].

Finally, the percentage of strains susceptible to meropenem was $41 \%$ for EC, $66.7 \%$ for SP, and less than $25 \%$ for the others, consistent with other studies. However, most clinicians consider carbapenems to be the class of choice for severe infections caused by ESBL-producing Enterobacteriaceae [34, 35]. Carbapenems-resistance of PA is the most typical and frequent example of resistance induced by developing cell membrane impermeability [38]. Furthermore, the enzymatic inactivation of carbapenems is the most common resistance mechanism in A. Baumannii [32]. Carbapenem-resistant Enterobacteriaceae (CRE) represents an immediate threat to public health that requires urgent and aggressive action. Community-wide infections are likely to lead to a dramatic increase in the practical use of carbapenems [39, 40]. A review article reported that the median prevalence of resistance to chloramphenicol in Enterobacteriaceae, isolated from patients with febrile illness, ranged from $31.0-94.2 \%$.

\section{Conclusion}

The findings confirm the ongoing elevated prevalence of multidrug-resistant bacteria in Bukavu, not withdrawing that the rates found can even be underestimated. In most cases worldwide, the risk factors for antimicrobial resistance are insufficient infection control in hospitals, inadequate public health systems for antimicrobial stewardship, inadequate knowledge of prescribers and users, advertising, and pharmaceutical companies' impact. The observed expansion requires that hospital therapeutic committees set up effective control and clinical management systems and define the right combinations of antibiotics.

\section{Abbreviations}

AG: Aminoglycosides

\section{CB: Citrobacter}

CDCP: Centers for Disease Control and Prevention

CRE: Carbapenem-Resistant Enterobacteriaceae 
CSL: Saint Luc Clinic

DRC: Democratic Republic of Congo

EB: Enterobacter spp

EB RC3G: Enterobacteriaceae resistant cephalosporin 3rd generation -

EC: Escherichia coli

EF: Enterococcus faecalis

ESBLE: Extended-spectrum beta-lactamase-producing Enterobacteriaceae

FAO: Food and Agriculture Organization of the United Nations

GLASS: Global Antimicrobial Surveillance System

HBP: BIO-PHARM hospital

HGP: Hospital General de Panzi

KP: Klebsiella pneumoniae

MDR: MultiDrug Resistant

MM: Morganella morganii

NG: Neisseria gonorrhea

NMDR : Non-MultiDrug Resistant

PA : Pseudomonas aeruginosa

PDR : PanDrug-Resistant

PM : Proteus mirabilis

SA : Staphylococcus aureus

SE: Salmonella enterica

SP: Streptococcus pyogenes

STI: Sexually transmitted infections

TB: Tuberculosis

WHO: World Health Organization

WOAH: World Organization for Animal Health

XDR: Extended Drug-Resistant

Declarations 


\section{Ethics and consent to participate}

All methods were carried out in accordance with relevant guidelines and regulations. All experimental protocols were approved by the research committee of the Faculty of Medicine (UOB). As retrospective study, informed consent was waived by institutional ethics review board of the Official University of Bukavu.

\section{Consent for publication}

Not applicable

\section{Availability of data and material}

The datasets used and/or analysed during the current study are available from the corresponding author on reasonable request.

\section{Conflicts of interest/Competing interests}

The authors declare that they have no competing interests

\section{Funding}

No funding

\section{Authors' contributions}

C.A.I and P.B.M. designed the protocol, collected data, and did the first analysis. F.M.K. and P.W. did the literature search and wrote the first draft. J.N.K validated the protocol, revised data analysis, and wrote the final draft. All authors reviewed the manuscript.

\section{Acknowledgements}

We thank the staff in the Bacteriology units at Panzi hospital, Biopharma Hospital, and Cliniques Saint Luc for their assistance.

\section{References}

1. Magiorakos AP, Srinivasan A, Carey RB, Carmeli Y, Falagas ME, Giske CG, Harbarth S, Hindler JF, Kahlmeter G, OlssonLiljequist B, Paterson DL, Rice LB, Stelling J, Struelens MJ, Vatopoulos A, Weber JT, and Monnet DL Multidrugresistant, extensively drug-resistant, and pandemic drug-resistant bacteria: an international expert proposal for interim standard definitions for acquired resistance. Clin Microbiol Infect 2012; 18: 268-281

2. Basak S, Singh P, Rajurkar M. Multidrug-Resistant, and Extensively Drug-Resistant Bacteria: A Study. J Pathogens. 2016. http://dx.doi.org/10.1155/2016/4065603

3. WHO Antimicrobial resistance: global report on surveillance. 2014. http://apps.who.int/iris/bitstream/10665/112642/1/9789241564748_eng.pdf?ua=1. Accessed 5 January 2021

4. Lim C, Takahashi E, Hongsuwan M, Wuthiekanun V, Thamlikitkul V, Hinjoy S, Day NPJ, Peacock SJ, and Limmathurotsakul $\mathrm{D}$ Epidemiology and burden of multidrug-resistant bacterial infection in a developing country. eLife 5: e18082. 2016 doi:7554/eLife.18082

5. Laxminarayan R, Duse A, Wattal C, Zaidi AK, Wertheim HF, Sumpradit N, Vlieghe E, Hara GL, Gould IM, Goossens H, Greko C, So AD, Bigdeli M, Tomson G, Woodhouse W, Ombaka E, Peralta AQ, Qamar FN, Mir F, Kariuki S, Bhutta ZA, 
Coates A, Bergstrom R, Wright GD, Brown ED, Cars O. Antibiotic resistance-the need for global solutions. Lancet Infect Dis 2013;13(12):1057-98

6. Albrechtova K, Dolejska M, Cizek A, Tausova D, Klimes J, Bebora L, and Literak I .Dogs of nomadic pastoralists in northern Kenya are reservoirs of plasmid-mediated cephalosporin- and quinolone-resistant Escherichia coli, including pandemic clone B2-025-ST131. Antimicrob Agents Chemother 2012;56:4013-4017

7. Beena ET, Shanmugam P, Malaisamy M, Ovung S, Suresh C, Subbaraman R, Adinarayanan S, and Nagarajan K. Psycho-Socio-Economic Issues Challenging Multidrug-Resistant Tuberculosis Patients: A Systematic Review. PLoS 2016;11(1).e0147397 doi: 1371/journal.pone.0147397

8. CDC Centers for Disease Control and Prevention. A Public Health Action Plan to Combat Antimicrobial Resistance. 2013. http://www.cdc.gov/drugresistanc/pdf/2010/Interagency-ActionPlanPreClearance-03-2011.pdf. Accessed 5 January 2021.

9. Agaba P, Tumukunde J, Tindimwebwa JVB, Kwizera A. Nosocomial bacterial infections and their antimicrobial susceptibility patterns among patients in Ugandan intensive care units: a cross-sectional study. BMC Res Notes 2017; 10:349.doi: 1186/s13104-017-2695-5

10. Dekraker M, Davey P, Grundmann H. Mortality and hospital stay associated with resistant Staphylococcus aureus and Escherichia coli bacteremia: estimating the burden of antibiotic resistance in Europe. PLoS Med 2011;8: e1001104

11. Van den Hof S, Collins D, Hafidz F, Beyene D, Tursynbayeva A, and Tiemersma E. The socioeconomic impact of multidrug-resistant tuberculosis on patients: results from Ethiopia, Indonesia, and Kazakhstan. BMC Infect Dis 2016; 16(1): 470.doi: 1186/s12879-016-1802-x

12. Bell BG, Schellevis F, Stobberingh E, Goossens H, Pringle M. A systematic review and meta-analysis of the effects of antibiotic consumption on antibiotic resistance. BMC Infect Dis 2014; 14:13.

13. Kadima JN, Nyandwi JB, Kayitana Cl, Mashaku A. Assessing Pharmaceutical Equivalence of Generic Antibiotics Using in vitro Antimicrobial Susceptibility of Some Hospital Strains in Rwanda. JAMMR 2016; 15(1):1-8. https://doi.org/10.9734/BJMMR/2016/25137

14. Habyalimana V, Kalenda NT, Mbinze JM, Dispas A, Loconon AY, Sacré PY, Widart J, De Tullio P, Counerotte S, Kadima NJL, Ziemons E, Hubert P, Marini RD. Analytical tools and strategic approach to detecting poor-quality medicines, identify unknown components, and timely alerts for appropriate measures: A case study of antimalarial medicines. Am J of Analytical Chemistry 2015; 6:977-994

15. OMS Premier rapport de l'OMS sur la résistance aux antibiotiques : une menace grave d'ampleur mondiale. http://www.who.int/mediacentre/news/releases/2014/amr- report/fr/. 2014. Accessed 21 Maiy 2018

16. Okeke IN, Laxminarayan R, Bhutta ZA, Duse AG, Jenkins P, O'Brien TF, Pablos-Mendez A, Klugman KP. Antimicrobial resistance in developing countries. Part I: recent trends and current status. Lancet Infect Dis 2005; 5(8):481-93

17. Irenge L M, L Kabego; F B Kinunu; M Itongwa; P N Mitangala; J-L Gala; R B Chirimwami. Antimicrobial resistance of bacteria isolated from patients with bloodstream infections at a tertiary care hospital in the Democratic Republic of the Congo. SAMJ 2015; 105(9):752-755

18. Salama B, Bavurhe BZ, Kadima NJ. Management of Acute Respiratory Infections in Children under Five by Selfmedication and Prescription of Antibiotics in Bukavu. IJTDH 2019; 40(4): 1-10.doi:

10.9734/IJTDH/2019/v40i430234

19. EUCAST Détermination de la sensibilité aux antibiotiques Méthode de diffusion en gélose, version 4.0, 2014. PDF (the European Committee for Antimicrobial Susceptibility Testing). http://www.eucast.org/

20. CA-SFM2017 Antibiogram Committee of the French Microbiology Society (ACFM). Report 2000-2001]. Pathol Biol (Paris) 48(9):832-71. [Article in French] 
21. CLSI (2012) Clinical and Laboratory Standards Institute, "Performance standards for antimicrobial susceptibility testing: 22nd informational supplement," CLSI Document M100-S22, Clinical and Laboratory Standards Institute, Wayne, Pa, USA, View at Google Scholar

22. WHO 2018 http://www.who.int/news-room/fact-sheets/detail/antimicrobial-resistance Accessed 26 May 2019

23. IRSST Institute Robert Sauvé of Research in Occupational Health and Safety. http://www.irsst.qc.ca/en/

24. Minardi D, Gianluca d'Anzeo, Cantoro D, Conti A, and Muzzonigro G (2011) Urinary tract infections in women: etiology and treatment options Int J Gen Med 2011; 4: 333-343

25. Anderson DJ, Moehring RW, Sloane R, Schmader KE, Weber DJ, Fowler VG Jr, Smathers E, Sexton DJ. Bloodstream infections in community hospitals in the 21st century: a multicenter cohort study. PLoS One 2014; 18;9(3): e91713.doi: 10.1371/journal.pone.0091713

26. Muvunyi CM, Masaisa F, Bayingana C, Mutesa L, Musemakweri A, Muhirwa G, and Claeys GW. Decreased Susceptibility to Commonly Used Antimicrobial Agents in Bacterial Pathogens Isolated from Urinary Tract Infections in Rwanda: Need for New Antimicrobial Guidelines. Am. J. Trop. Med. Hyg. 2011; 84(6): 923-928

27. Reseau BMR Raisin. Surveillance des bactéries multi-résistantes dans les établissements de santé en France. http://www.invs.sante.fr/Dossiersthematiques/Maladiesinfectieuses/Resistance-aux-anti-infectieux/Publications-dereference Accessed 26 May 2019

28. Gopal Rao G, Batura D, Batura N, Nielsen PB. Key demographic characteristics of patients with bacteriuria due to extended-spectrum beta-lactamase (ESBL)-producing Enterobacteriaceae in a multiethnic community in North West London. Infect Dis (Lond) 2015; 47(10):719-24.doi: 10.3109/23744235.2015.1055588

29. Bala M, Singh V, Bhargava A, Kakran M, Joshi Naveen C, and Bhatnagar R. Gentamicin Susceptibility among a Sample of Multidrug-Resistant Neisseria gonorrhoeaelsolates in India. Antimicrob Agents Chemother 2016; 60(12): 7518-7521 doi: 1128/AAC.01907-16

30. Garneau-Tsodikova S, and Labby Mechanisms of Resistance to Aminoglycoside Antibiotics: Overview and Perspectives. Medchemcomm 2016;7(1):11-27.doi: 10.1039/C5MD00344J

31. Stalenhoef J, van Nieuwkoop Cees, Menken PH, Sandra T, Bernards Hendrik W Elzevier BHW, van Dissel Jaap T Intravesical Gentamicin Treatment for Recurrent Urinary Tract Infections Caused by Multidrug-Resistant Bacteria. The Journal of Urology 2018; 201(3) DOI: 1016/j.juro.2018.10.004

32. Stije JL, van Leth $\mathrm{F}$, Tarekegn $\mathrm{H}$, and Schultz C. Antimicrobial drug resistance among clinically relevant bacterial isolates in sub-Saharan Africa: a systematic review J Antimicrob Chemother 2014;69: 2337 -2353 DOI:10.1093/jac/dku176

33. Tadesse BT, Ashley EA, Ongarello S, Havumaki J, Wijegoonewardena M, González IJ, and Dittrich S . Antimicrobial resistance in Africa: a systematic review. BMC Infect Dis 2017; 17:616. DOI: [1186/s12879-017-2713-1

34. Hussain, T. Pakistan on the verge of potential epidemics by multidrug-resistant pathogenic bacteria. Adv Life Sci 2015; 2(2): 46-47

35. Petty NK, Ben Zakour NL, Stanton-Cook M, Skippington E, Totsika M, Forde BM, Phan MD, Gomes Moriel D, Peters KM, Davies M, Rogers BA, Dougan G, Rodriguez-Baño J, Pascual A, Pitout JD, Upton M, Paterson DL, Walsh TR, Schembri MA, Beatson SA. Global dissemination of a multidrug-resistant Escherichia coli clone. Proc Natl Acad Sci U S A 2014; 111:5694-9.

36. Doi Y, Park YS, Rivera JI, Adams-Haduch JM, Hingwe A, Sordillo EM, Lewis JS 2nd, Howard WJ, Johnson LE, Polsky B, Jorgensen JH, Richter SS, Shutt KA, Paterson DL. Community-associated extended-spectrum beta-lactamase (ESB) - producing Escherichia coli infection in the United States. Clin Infect Dis 2013; 56:641-648

37. Rogers BA, Ingram PR, Runnegar N, Pitman MC, Freeman IJ, Athan E, Havers SM, Sidjabat HE,Jones M, Gunning E, De Almeida M, Styles K, Paterson DL, Community-onset Escherichia coli expanded-spectrum cephalosporins in low- 
prevalence countries. Antimicrob Agents Chemother 2014; 58:2126-34

38. Marchou B, Michea-Hamzehpour M, Lucain C, Pechère JC. Development of beta-lactam-resistant Enterobacter cloacae in mice. J Infect Dis 1987; 156(2):369-373

39. Pannaraj PS, Bard JD, Cerini C, Weissman SJ. Pediatric carbapenem-resistant Enterobacteriaceae in Los Angeles, California, a high-prevalence region in the United States. Pediatr Infect Dis J 2015; 34:11-6

40. Khajuria A, Praharaj AK, Kumar M, Grover N. Emergence of Escherichia coli, Co-Producing NDM-1 and OXA-48 Carbapenemases, in Urinary Isolates, at a Tertiary Care Centre at Central India. J Clin Diagn Res 2014;8(6):DC014.doi: 10.7860/JCDR/2014/7952.4413

\section{Figures}

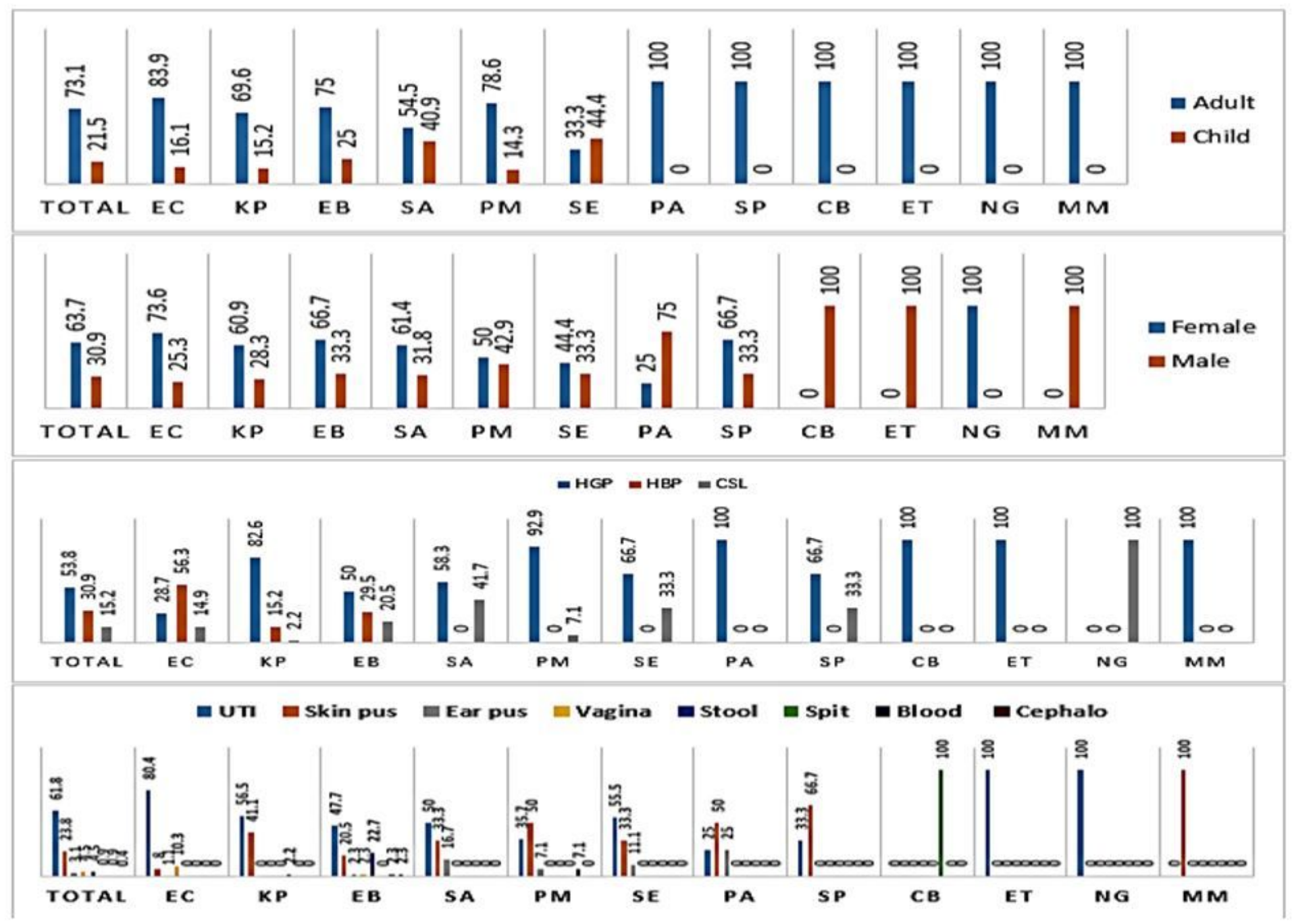

Figure 1

Frequency of MDR strains disaggregated by age, gender, hospital, specimens 